\title{
Physical activity and fitness are associated with verbal memory, quality of life and depression among nursing home residents: preliminary data of a randomized controlled trial
}

Haritz Arrieta' ${ }^{1}$ Chloe Rezola-Pardo ${ }^{1}$, Iñaki Echeverria ${ }^{1}$, Miren Iturburu², Susana Maria Gil ${ }^{1}$, Jose Javier Yanguas ${ }^{2}$, Jon Irazusta ${ }^{1}$ and Ana Rodriguez-Larrad ${ }^{1 *}$ (D)

\begin{abstract}
Background: Few studies have simultaneously examined changes in physical, cognitive and emotional performance throughout the aging process.

Methods: Baseline data from an ongoing experimental randomized study were analyzed. Physical activity, handgrip, the Senior Fitness Test, Trail Making Test A, Rey Auditory-Verbal Learning Test, Quality of Life-Alzheimer's Disease Scale (QoL-AD) and the Goldberg Depression Scale were used to assess study participants. Logistic regression models were applied. Trial registration: ACTRN12616001044415 (04/08/2016).

Results: The study enrolled 114 participants with a mean age of 84.9 (standard deviation 6.9) years from ten different nursing homes. After adjusting for age, gender and education level, upper limb muscle strength was found to be associated with Rey Auditory-Verbal Learning Test [EXP(B): 1.16, 95\% confidence interval (CI): 1.04-1.30] and QoL-AD [EXP(B): 1.18, 95\% Cl: 1.06-1.31]. Similarly, the number of steps taken per day was negatively associated with the risk of depression according to the Goldberg Depression Scale [EXP(B): 1.14, 95\% Cl: 1.000-1.003]. Additional analyses suggest that the factors associated with these variables are different according to the need for using an assistive device for walking. In those participants who used it, upper limb muscle strength remained associated with Rey Auditory-Verbal Learning Test [EXP(B): 1.21, 95\% Cl: 1.01-1.44] and QoL-AD tests [EXP(B): 1.19, 95\% Cl: 1.02-1.40]. In those individuals who did not need an assistive device for walking, lower limb muscle strength was associated with Rey Auditory-Verbal Learning Test [EXP(B): 1.35, 95\% Cl: 1.07-1.69], time spent in light physical activity was associated with QoL-AD test $[\operatorname{EXP}(B): 1.13,95 \% \mathrm{Cl}: 1.00-1.02]$, and the number of steps walked per day was negatively associated with the risk of depression according to the Goldberg Depression Scale [EXP(B): $1.27,95 \% \mathrm{Cl}: 1.000-1.004]$.

(Continued on next page)
\end{abstract}

\footnotetext{
* Correspondence: ana.rodriguez@ehu.eus

${ }^{1}$ Department of Physiology, Faculty of Medicine and Nursing, University of the Basque Country (UPV/EHU), Barrio Sarriena s/n, E-48940 Leioa, Bizkaia, Spain

Full list of author information is available at the end of the article
} 
(Continued from previous page)

Conclusions: Muscle strength and physical activity are factors positively associated with a better performance on the Rey Auditory-Verbal Learning Test, QoL-AD and Goldberg Depression Scale in older adults with mild to moderate cognitive impairment living in nursing homes. These associations appeared to differ according to the use of an assistive device for walking. Our findings support the need for the implementation of interventions directed to increase the strength and physical activity of individuals living in nursing homes to promote physical, cognitive and emotional benefits.

Trial registration: ACTRN12616001044415 (04/08/2016).

Keywords: Physical activity, Exercise, Cognition, Quality of life, Depression, Older adults, Nursing home

\section{Background}

Aging is a dynamic and progressive decline in physical and cognitive performance leading to the loss of overall function for the activities of daily living. Increasing evidence supports an interaction between physical and cognitive impairment within the cycle of decline associated with aging [1]. In other words, brain health is strongly linked to physical health, and physical performance is, to a large extent, thought to be cognitively mediated.

Moreover, physical activity and exercise, as beneficial lifestyle factors, may attenuate or prevent cognitive decline associated with aging [2-4]. Multiple studies have highlighted the beneficial effects of aerobic exercise [5,6], resistance training [7] and physical activity [8,9] on cognitive function in older adults, although the neurophysiologic mechanisms driving these effects are not well understood. Further, physical and cognitive function could be linked to health-related quality of life [10] (QoL) and affective conditions [11] in older adults. Previous works examining these relationships are largely restricted to people with cognitive impairments. Nevertheless, a longitudinal study performed in healthy older community-dwelling adults, found that greater levels of physical activity were independently associated with better long-term health-related QoL in a follow-up period of six years [12].

Despite the evidence supporting associations between physical, cognitive and affective aspects related to the aging process, few studies considered these conditions simultaneously. In addition, to our knowledge, no such studies have focused on older adults who live in nursing home settings, although this is one of the fastest-growing demographics worldwide [13]. Older adults living in nursing homes are characterized by old age, a high prevalence of multimorbidity, functional impairment, severe cognitive deficits, depression, and very low physical activity [14]. However, there is a subgroup of residents that maintains the ability to walk and some of these residents even present wandering behavior [15].

Many residents of nursing homes require assistive walking devices to carry out the activities of daily living.
The need to incorporate the upper limbs for getting up from a chair or for discharging the body weight while walking will affect their physical performance, specifically those features associated with muscle strength of the upper limbs. Therefore, it may be pertinent to think that, if associations between physical, cognitive and affective aspects exist, they could be conditioned by the need to use assistive devices for walking.

Further, although recent initiatives have aimed at improving the quality of care in nursing homes [16, 17], physical and social inactivity remain a concern in these institutions $[18,19]$. Investigating the associations between physical, cognitive and affective aspects in older adults living in nursing homes may provide valuable insights for guiding clinical practice and consequently support nursing home management in evidence based decisions.

With this in mind, we sought to evaluate the associations between physical fitness and physical activity, and cognitive performance, QoL and depression risk in older adults living in long-term (LT) nursing homes. We hypothesized that better physical fitness and higher levels of physical activity might be independent factors for better cognitive performance, better QoL and lower risk of depression in older adults living in LT nursing homes. Secondarily, we examined whether these potential associations could differ for residents who require an assistive device for walking (for example crutches or canes).

\section{Methods}

\section{Study design and participants}

Data from a multicenter, randomized study carried out in ten LT nursing homes between October 2016 and June 2017 were available for analysis in this study. Seven residents out of 206 potential participants did not meet the inclusion criteria, 83 declined to participate, and two did not sign the informed consent document, leaving 114 participants. A flow diagram depicting the selection process is shown in Fig. 1. Details of the methods for designing and conducting the study were previously published [20]. 


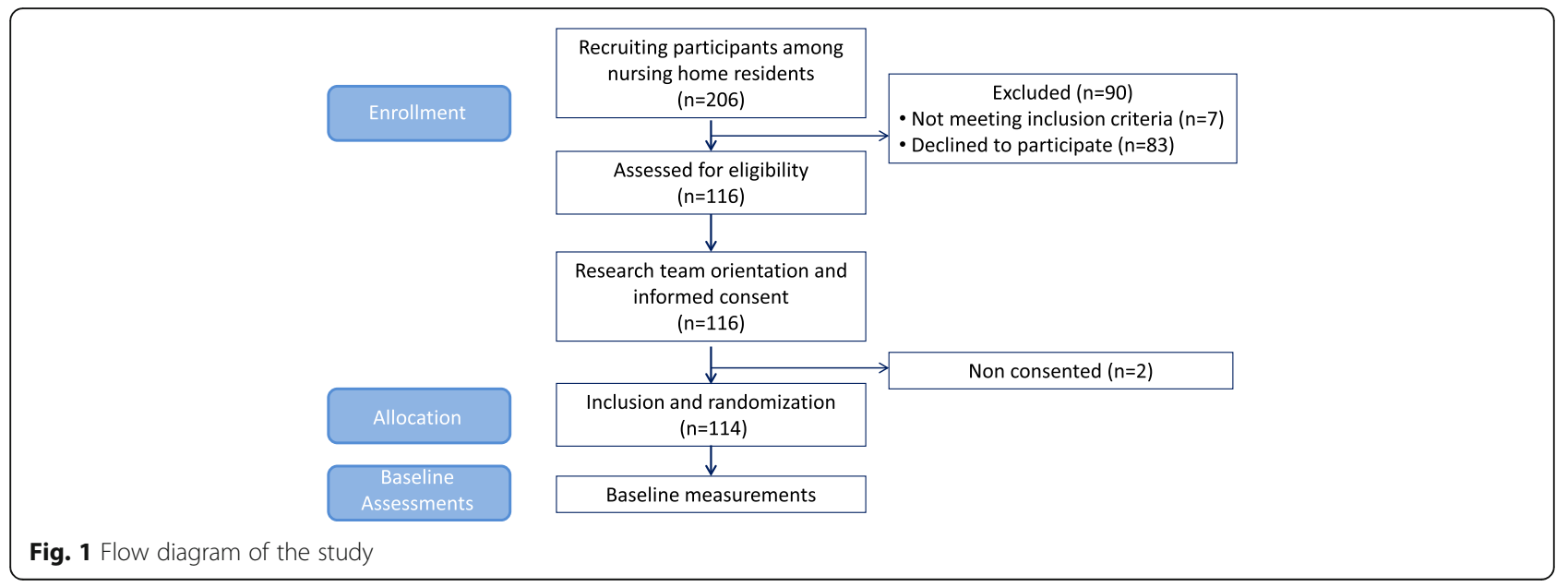

Briefly, eligible participants included men and women aged $\geq 70$ years, who scored $\geq 50$ on the Barthel Index [21], scored $\geq 20$ on the MEC-35 Test [22] (an adapted and validated version of the Mini Mental State Examination in Spanish), and who were able to stand and walk independently for at least ten meters. The study was approved by the Committee on Ethics in Research at the University of the Basque Country (Humans Committee Code M10/2016/105). The protocol is registered under the Australian and New Zealand Clinical Trials Registry (ANZCTR) with the identifier: ACTRN12616001044415. Date of registration: 04/08/2016.

\section{Measurements}

Physical activity performed by the participants was objectively recorded with an accelerometer (Actigraph GT3X model, Actigraph LLC, Pensacola, FL, USA), worn on the hip with a belt for seven days. Activity was recorded using 60-s epochs. Data files recorded on the accelerometers were downloaded and processed with Actilife software (version 6, Actigraph, 2012). The analyzed variables were: number of steps per day and number of minutes per day spent in intensity specific categories. Selecting cut-off points to classify the intensity of physical activity in older people was difficult because there is no current consensus in the scientific literature. Thus, we followed the protocol developed by Freedson and collaborators [23], where the cut-off point for light physical activity was set in the range of 100-1951 counts per minute (cpm), and moderate to vigorous physical activity (MVPA) was defined as all activity $\geq 1952 \mathrm{cpm}$. The number of minutes per day at different intensities was calculated by summing all minutes where the count met the criterion for the specific intensity and then dividing by the number of valid days.
Physical fitness was assessed through the handgrip strength test [24] (Jamar dynamometer) of the dominant upper limb and the Senior Fitness Test [25] (SFT), a battery of six independent tests encompassing: chair stand test (lower limb strength), arm curl test (upper limb strength), six minute walking test (6MWT) (aerobic endurance), chair sit and reach test (lower limb flexibility), back scratch test (upper limb flexibility) and the 8 -ft up and go test (dynamic balance).

Cognitive performance tests were evaluated by the same trained neuropsychologist; assessments were carried out individually in participants own rooms. The MEC-35 test [22] was used for screening and scaling cognitive impairment. Trail Making Test A [26] was administered to assess the speed of information processing, and more concretely, aspects of motor control, motor speed and visual scanning speed. To administer the Trail Making Test A, participants were instructed to draw lines connecting consecutively numbered circles as quickly as possible. The resultant score is the number of seconds required to complete the task; shorter time indicates better performance. A Spanish validated version of the Rey Auditory-Verbal Learning Test [27] (RAVLT) was administered to participants to assess verbal memory. The test lasted approximately $15 \mathrm{~min}$. Consisted of two lists that had to be read aloud; one of 15 words (List A) and a new list of 15 different words (List B). The participant was asked to freely recall the words read aloud by the evaluator in List A. Four more trials were performed in the same way. After five trials, the List B was presented, and a free recall trial was asked for the words in List B. Immediately after, participants were asked to freely recall again the words in List A. Twenty minutes later the participants were asked to recall the words on List A. Then, the evaluator read aloud the 30 words from List A and List B, and the participants 
were asked to recognize the words from List A. Even though RALVT can be analyzed trial by trial, the authors recommend to establish different measures for its clinical use [28]. In this study, the Total Learning measure (RAVLT-AT) was calculated, which evaluates the capacity to recall and to accumulate words through the 5 learning trials. The RAVLT-AT score resulted from the sum of the five consecutive learning trials (trial $1+$ trial $2+$ trial $3+$ trial $4+$ trial5).

Health-related quality of life was evaluated by a Spanish validated version of the Quality of LifeAlzheimer's Disease Scale [29] (QoL-AD). Considering that many of the participants showed different levels of cognitive impairments or were at risk to develop dementia during the program, we selected the QoLAD scale as the best tool for assessing health-related quality of life in our participants. The scale comprises 13 items (physical health, energy, mood, living situation, memory, family, marriage, friends, self as a whole, ability to do chores, ability to do things for fun, money and life as a whole). Each item is answered according to a Likert scale from 1 (poor) to 4 (excellent), for a total score between 13 and 52, with higher scores indicating better QoL.

Depression was measured by the Goldberg Depression Scale [30] (GDS), which comprises four screening items and five supplementary ones. Participants who respond positively to two or more screening items go on responding to the following five. Participants scoring two or more have a $50 \%$ chance of having a clinically important disturbance of depression.

\section{Statistical analysis}

Continuous variables were expressed as means with standard deviations (SD), and categorical variables as frequency counts and percentages (\%). Taking into account that up-to-date reference values for the dependent variables MEC-35, Trail Making A, RAVLT-AT, and QoL-AD have not been reported for older adults living in nursing homes, the cut-off point in the current study was determined according to the median, as used in other studies [31, 32]. Thus, the dependent continuous variables were transformed into binary variables according to whether they had a value above or below their median. Comparisons of sociodemographic characteristics, physical fitness and physical activity between participants who were above or below the median on MEC-35, Trail Making A, RAVLT-AT, QoL-AD and Goldberg Depression Scale were performed using appropriate statistical tests according to the type and distribution of the data: $t$-test or Mann-Whitney $U$-test for continuous variables and Chi-squared test for categorical variables. A $p$ value $<0.05$ was considered significant. We also performed logistic regressions, with demographic, accelerometry and physical fitness data as independent variables, and cognitive performance tests, health-related quality of life and depression risk data as dependent variables. Those variables that reached a $p$ value $<0.05$ on univariate analysis were considered eligible for entry into the multiple logistic regression analysis. Backward regression models were then fitted. All multiple models were adjusted for age and gender. In addition, HosmerLemershow goodness-of-fit, Omnibus and Nagelkerke's $\mathrm{R}^{2}$ values for each model were specified. A HosmerLemershow test was used to determine the goodnessof-fit of the models, that is, to determine if the observed event rates matched expected ones; a number closest to 1 show a better goodness of fit. Omnibus was used to test whether the explained variance was significantly greater than the unexplained variance; a $p$ value $<0.05$ was considered significant. Nagelkerke's $R^{2}$ values estimated the proportion of the dependent variable explained by the independent variables. Then, the sample was divided according to the need of any assistive device for walking, and multiple regression models were performed for each group. Statistical analysis was performed using SPSS v.21 software.

\section{Results}

\section{Characteristics of study participants}

This study adheres to the Consolidated Standards of Reporting Trials (CONSORT) guidelines. The study included 114 participants from ten LT nursing homes. Accelerometer monitoring showed that they performed very low levels of physical activity during the day (Table 1). Further, $46 \%$ of the participants scored lower than the median level of QoL-AD, and 25\% of the participants had a $50 \%$ chance of having a clinically important disturbance of depression according to the Goldberg depression scale. In addition, $55 \%$ of the participants needed an assistive device for carrying out the activities of daily living.

\section{Participant characteristics according to their performance on MEC-35 test, trail making a test, RAVLT-AT test, QoL- $A D$ test and Goldberg depression scale}

Individuals who scored below the median of the sample on the MEC-35 test presented less flexibility of the lower limbs $(p=0.011)$ compared to the participants scoring equal to or higher than the median of the sample (Table 2). Similarly, participants who scored below the median of the sample on the RAVLT-AT test presented lower muscle strength in both upper and lower limbs (Chair stand test $p=0.009$; Arm curl test $p=0.005$ ) along with lower flexibility in the chair sit-and-reach test $(p=0.015)$ than individuals scoring equal to or higher than the median of the sample. In addition, those perceiving their QoL below the median of the sample presented lower levels of physical activity (Steps/day $p=0.007$; Light physical 
Table 1 Baseline characteristics of the participants $(n=114)$

\begin{tabular}{|c|c|}
\hline Variable & Value \\
\hline Age (yr) mean (SD) & $84.9(6.9)$ \\
\hline $70-79$ (yr) \%(n) & $22.8 \%(26)$ \\
\hline $80-89$ (yr) \%(n) & $53.5 \%(61)$ \\
\hline$\geq 90(y r) \%(n)$ & $23.7 \%(27)$ \\
\hline \multicolumn{2}{|l|}{ Sex } \\
\hline Men \%(n) & $28.9 \%(33)$ \\
\hline Women \%(n) & $71.1 \%(81)$ \\
\hline Barthel Index mean (SD) & $80.6(12.9)$ \\
\hline MEC-35 mean (SD) & $27.5(3.8)$ \\
\hline BMI $\left(\mathrm{kg} / \mathrm{m}^{2}\right)$ mean $(\mathrm{SD})$ & $28.2(5.1)$ \\
\hline \multicolumn{2}{|l|}{ Education } \\
\hline$\leq 12$ years $\%(n)$ & $92 \%(104)$ \\
\hline$>12$ years \%(n) & $8 \%(10)$ \\
\hline Steps/day mean (SD) & $1162.3(1776.4)$ \\
\hline Light physical activity (min/day) mean (SD) & 86.7 (59.6) \\
\hline MVPA (min/day) mean (SD) & $1.3(3.1)$ \\
\hline Handgrip (Kg) mean (SD) & $21.1(8.1)$ \\
\hline Chair stand test (rep) mean (SD) & $7.6(3.9)$ \\
\hline Arm curl test (rep) mean (SD) & $12.2(4.3)$ \\
\hline 6-min walk test $(\mathrm{m})$ mean (SD) & $230.7(95.9)$ \\
\hline Chair sit-and-reach test (cm) mean (SD) & $-11.8(9.3)$ \\
\hline Back scratch test $(\mathrm{cm})$ mean $(\mathrm{SD})$ & $-21.3(12.9)$ \\
\hline 8-ft up-and-go test (sec) mean (SD) & $15.4(9.3)$ \\
\hline
\end{tabular}

Abbreviations: MEC-35 Mini Examen Cognoscitivo-35, BMI Body Mass Index, MVPA moderate-vigorous physical activity, rep repetitions

activity $p=0.013$ ) and lower levels of muscle strength (Handgrip test $p=0.032$; Chair stand test $p=0.025$; Arm curl test $p=0.002$ ) compared to those perceiving their QoL equal to or higher than the median (Table 3). Older adults with a $50 \%$ chance of having a clinically relevant disturbance of depression according to the Goldberg depression scale scored lower in terms of physical activity (Steps/day $p=0.004$; Light physical activity $p=0.009$ ) and lower body muscle strength (Chair stand test $p=0.048$; Arm curl test $p=$ 0.004 ) than older adults with no risk of depression. There were no significant differences in physical fitness or physical activity characteristics of the participants in this study between those individuals above and below the median in Trail Making A test performance.

\section{Logistic regression models}

We applied univariate logistic regression models to determine associations between each dependent and independent variable (Appendices 1, 2, 3, 4, 5 and 6). Those independent variables that reached a $p$ value $<0.05$ on the univariate analysis were included in the multiple logistic regression models that are detailed below (Tables 4, 5, 6 and 7).

\section{Factors associated with RAVLT-AT test performance}

After adjusting for age, gender and education level, the variables that were associated with a RAVLT-AT test score equal to or above the median of the sample were upper limb muscle strength and lower limb flexibility (Table 4). To address the second objective of the study, we divided the sample according to the need of any assistive device for walking and performed the same regression model in each group. After adjusting for age, gender and education level, the lower limb muscle strength was associated with a score in the RAVLT-AT test equal to or above the median in those individuals who did not need any assistive device for walking. Upper limb muscle strength and flexibility in the chair sit-andreach test were associated with a score equal to or higher than the median on the RAVLT-AT test in those individuals needing any assistive device for walking.

\section{Factors associated with QoL-AD test performance}

Regarding QoL, the multiple regression model performed with the whole sample revealed that upper limb muscle strength was associated with a score equal to or higher than the median on the QoL-AD test (Table 5). When we stratified the sample according to the use of any assistive device for walking, light physical activity was associated with a QoL-AD score equal to or higher than the median in those individuals who did not need any help for walking, while upper limb muscle strength appeared to be associated for those needing assistance.

\section{Factors associated with Goldberg depression scale performance}

In the regression model performed with the whole sample, the number of steps/day walked by the participants was associated with the absence of risk of depression according to the Goldberg Depression Scale (Table 6). In those individuals who did not need any assistive device for walking, the number of steps/ day was again associated with the absence of risk of depression. In addition, in those individuals needing walking assistance, female gender was associated with a $50 \%$ greater risk of depression.

\section{Factors associated with MEC-35 test performance}

Finally, when the whole sample was analyzed, chair sit and reach test was associated with performance on the MEC-35 test equal to or above the median of the sample (Table 7). No independent variables were found to be associated with higher score on MEC-35 performance 
Table 2 Characteristics of the participants according to their MEC-35 test, Trail Making A test and RAVLT-AT test performance

\begin{tabular}{|c|c|c|c|c|c|c|}
\hline \multirow[b]{2}{*}{ Variables } & \multicolumn{2}{|l|}{ MEC-35 } & \multicolumn{2}{|l|}{ Trail Making A } & \multicolumn{2}{|l|}{ RAVLT-AT } \\
\hline & $<$ median & $\geq$ median & $<$ median & $\geq$ median & $<$ median & $\geq$ median \\
\hline Age (yr) mean (SD) & $85.3(8.0)$ & $84.5(5.8)$ & $84.6(6.2)$ & $84.6(5.6)$ & $85.1(5.8)$ & $84.5(7.4)$ \\
\hline \multicolumn{7}{|l|}{ Sex } \\
\hline Men \% & $29.4 \%$ & $29.0 \%$ & $34.4 \%$ & $31.2 \%$ & $36.2 \%$ & $25.5 \%$ \\
\hline Women \% & $70.6 \%$ & $71.0 \%$ & $65.6 \%$ & $68.8 \%$ & $63.8 \%$ & $74.5 \%$ \\
\hline Barthel Index mean (SD) & $79.8(12.5)$ & $81.8(13.4)$ & $81.7(12.8)$ & $80.6(14.2)$ & $82.6(11.7)$ & $80.7(12.9)$ \\
\hline BMI $\left(\mathrm{kg} / \mathrm{m}^{2}\right)$ mean $(\mathrm{SD})$ & $28.6(5.5)$ & $27.8(4.8)$ & $28.0(5.3)$ & $28.0(5.1)$ & $27.4(4.6)$ & $28.8(5.6)$ \\
\hline \multicolumn{7}{|l|}{ Education } \\
\hline$\leq 12$ years $\%$ & $96.1 \%$ & $88.5 \%$ & $100 \%$ & $81.2 \%^{*}$ & $89.1 \%$ & $92.2 \%$ \\
\hline$>12$ years $\%$ & $3.9 \%$ & $11.5 \%$ & - & $18.8 \%$ & $10.9 \%$ & $7.8 \%$ \\
\hline Steps/day mean (SD) & $912.3(1326.1)$ & $1248.5(1967.1)$ & $1376.0(2575.2)$ & $1312.4(1649.8)$ & $888.7(702.8)$ & $1375.2(2363.9)$ \\
\hline Light physical activity (min/day) mean (SD) & $79.1(59.5)$ & $85.4(58.7)$ & $95.6(69.7)$ & $89.9(59.8)$ & $82.7(52.6)$ & $90.3(65.9)$ \\
\hline MVPA (min/day) mean (SD) & $0.7(0.6)$ & $1.8(4.2)$ & $1.9(5.2)$ & $0.6(0.6)$ & $0.9(1.0)$ & $1.7(4.5)$ \\
\hline Handgrip (Kg) mean (SD) & $19.9(6.9)$ & $21.8(8.6)$ & $22.3(8.9)$ & $21.8(8.2)$ & $20.9(7.0)$ & $21.2(7.5)$ \\
\hline Chair stand test (rep) mean (SD) & $7.2(3.4)$ & $7.9(4.5)$ & $8.3(4.0)$ & $7.4(4.3)$ & $6.5(3.7)$ & $8.8(3.9)^{* *}$ \\
\hline Arm curl test (rep) mean (SD) & $11.3(3.7)$ & $12.9(4.5)$ & $12.6(4.4)$ & $12.7(3.7)$ & $11.0(3.8)$ & $13.4(4.1)^{* *}$ \\
\hline 6-min walk test $(\mathrm{m})$ mean (SD) & $220.9(96.7)$ & $241.8(92.7)$ & $253.5(85.9)$ & $233.1(93.1)$ & $234.6(91.6)$ & $231.2(90.4)$ \\
\hline Chair sit-and-reach test $(\mathrm{cm})$ mean (SD) & $-13.4(8.8)$ & $-9.8(9.4)^{*}$ & $-11.7(8.9)$ & $-10.8(9.9)$ & $-13.6(8.5)$ & $-9.8(10.1)^{*}$ \\
\hline Back scratch test $(\mathrm{cm})$ mean $(\mathrm{SD})$ & $-23.5(13.1)$ & $-18.4(12.8)$ & $-23.1(14.0)$ & $-16.5(13.1)$ & $-21.9(13.8)$ & $-19.7(12.7)$ \\
\hline 8-ft up-and-go test (sec) mean (SD) & $16.2(8.8)$ & $14.4(9.5)$ & $13.4(6.5)$ & $14.4(7.0)$ & $14.9(6.7)$ & $14.5(8.3)$ \\
\hline
\end{tabular}

Abbreviations: MEC-35 Mini Examen Cognoscitivo-35, RAVLT-AT Rey Auditory-Verbal Learning Test-Total Learning, BMI Body Mass Index, MVPA moderate-vigorous physical activity, rep repetitions

${ }^{*} p<0.05$

${ }^{* *} p<0.01$

when the analysis was stratified according to the use of an assistive device for walking.

\section{Discussion}

The results of this study showed that physical fitness and, more specifically, upper limb muscle strength were associated with RAVLT-AT and QoL-AD tests in older adults living in LT nursing homes. Similarly, the number of steps taken by the participants per day was negatively associated with the risk of depression according to the Goldberg Depression Scale. Lower limb flexibility was also associated with a better score on the MEC-35 test. Additional analyses suggest that the factors associated with these variables are different according to the need for using an assistive device for walking. In those participants who used an assistive device for walking, upper limb muscle strength remained associated with RAVLTAT and QoL-AD tests. In those individuals who did not need any assistive device for walking, lower limb muscle strength was associated with RAVLT-AT test, the time spent in light physical activity proved to be associated with QoL-AD test, and the number of steps walked by the participants remained a factor negatively associated with the risk of depression according to the Goldberg Depression Scale.

The results of the current study partially support our hypothesis that better physical fitness and higher levels of physical activity might be factors associated with better performance in the RAVLT-AT test, the QoL-AD test, the MEC-35 test or the Goldberg Depression Scale. However, we found that specific parameters of physical fitness (muscle strength and the level of physical activity in particular) were associated with specific cognitive variables. Other studies have recently observed this specificity in the link between physical and cognitive performance in the older adult population. An intervention study [33] reported a dose-response effect of aerobic exercise on components of visuospatial function in a group of community-living older sedentary adults without cognitive impairment. Another prospective study [34] found a dose-response effect of resistance training on executive cognitive function of selective attention and conflict resolution among senior community-dwelling women aged 65 to 75 years. In addition, links between physical activity and processing speed have also been observed $[3,35,36]$. Nevertheless, to our knowledge, no study has assessed the specificity in the association between 
Table 3 Characteristics of the participants according to their performance on the QoL-AD Test and their depression risk assessed by the Goldberg Depression Scale

\begin{tabular}{|c|c|c|c|c|}
\hline \multirow[b]{2}{*}{ Variables } & \multicolumn{2}{|l|}{ QoL-AD Test } & \multicolumn{2}{|c|}{ Goldberg Depression Scale } \\
\hline & $<$ median & $\geq$ median & $50 \%$ risk Depression & No depression risk \\
\hline Age (yr) mean (SD) & $85.4(6.4)$ & $84.0(7.2)$ & $86.1(6.7)$ & $84.2(6.9)$ \\
\hline \multicolumn{5}{|l|}{ Sex } \\
\hline Men \% & $25.5 \%$ & $34.5 \%$ & $11.5 \%$ & $36.8 \%^{*}$ \\
\hline Women \% & $74.5 \%$ & $65.5 \%$ & $88.5 \%$ & $63.2 \%$ \\
\hline Barthel Index mean (SD) & $81.1(12.9)$ & $81.2(12.6)$ & $80.8(14.4)$ & $81.2(12.1)$ \\
\hline $\mathrm{BMI}\left(\mathrm{kg} / \mathrm{m}^{2}\right)$ mean $(\mathrm{SD})$ & $27.7(4.7)$ & $28.7(5.6)$ & $28.7(5.5)$ & $28.1(5.1)$ \\
\hline \multicolumn{5}{|l|}{ Education } \\
\hline$\leq 12$ years $\%$ & $93.5 \%$ & $89.1 \%$ & $96.2 \%$ & $89.3 \%$ \\
\hline$>12$ years $\%$ & $6.5 \%$ & $10.9 \%$ & $3.8 \%$ & $10.7 \%$ \\
\hline Steps/day mean (SD) & $742.40(727.20)$ & $1484.2(2266.8)^{* *}$ & $554.7(295.3)$ & $1339.7(1997.2)^{* *}$ \\
\hline Light physical activity (min/day) mean (SD) & $70.84(44.61)$ & $99.8(67.0)^{*}$ & $61.7(37.5)$ & $94.8(63.0)^{* *}$ \\
\hline MVPA (min/day) mean (SD) & $0.9(1.7)$ & $1.6(4.2)$ & $0.9(1.2)$ & $1.5(3.7)$ \\
\hline Handgrip (Kg) mean (SD) & $19.38(6.91)$ & $22.7(8.0)^{*}$ & $18.7(5.4)$ & $22.0(8.2)$ \\
\hline Chair stand test (rep) mean (SD) & $6.80(3.96)$ & $8.4(3.9)^{*}$ & $6.7(3.9)$ & $7.9(4.0)^{*}$ \\
\hline Arm curl test (rep) mean (SD) & $10.98(4.19)$ & $13.4(3.7)^{* *}$ & $10.4(3.0)$ & $12.9(4.2)^{* *}$ \\
\hline 6-min walk test $(\mathrm{m})$ mean (SD) & $219.92(75.90)$ & $242.3(100.8)$ & $221.8(72.5)$ & $235.4(95.8)$ \\
\hline Chair sit-and-reach test (cm) mean (SD) & $-11.56(9.29)$ & $-11.5(9.5)$ & $-12.9(8.7)$ & $-11.1(9.6)$ \\
\hline Back scratch test (cm) mean (SD) & $-21.22(15.12)$ & $-20.9(11.7)$ & $-20.2(15.1)$ & $-21.2(12.8)$ \\
\hline 8-ft up-and-go test (sec) mean (SD) & $16.34(8.88)$ & $13.41(6.2)$ & $15.5(7.3)$ & $14.5(7.8)$ \\
\hline
\end{tabular}

Abbreviations: QoL-AD Test Quality of Life-Alzheimer Disease Test, BMI Body Mass Index, MVPA moderate-vigorous physical activity, rep repetitions ${ }^{*} p<0.05$

${ }^{* *} p<0.01$

Table 4 Logistic regression models according to the RAVLT-AT performance adjusted by age, sex, and education level

\begin{tabular}{|c|c|c|c|}
\hline & \multicolumn{3}{|c|}{ Whole sample } \\
\hline & B & $\operatorname{EXP}(B)(95 \% \mathrm{Cl})$ & $p$-value \\
\hline Arm curl test & 0.15 & $1.16(1.04-1.30)$ & 0.009 \\
\hline Chair sit-and-reach test & 0.04 & $1.05(1.00-1.10)$ & 0.039 \\
\hline \multicolumn{4}{|c|}{$\begin{array}{l}\text { Variables in the model: chair stand test, arm curl test and chair } \\
\text { sit-and-reach test; Estimates are based on } n=95 \text { participants due } \\
\text { to missing values; Hosmer-Lemershow goodness of fit, } p=0.444 \text {; } \\
\text { Omnibus, } p=0.001 ; R^{2} \text { Nagelkerke }=0.175 \text {. }\end{array}$} \\
\hline & \multicolumn{3}{|c|}{ No aids for walking $(n=46)$} \\
\hline & B & $\operatorname{EXP}(B)(95 \% C l)$ & $p$-value \\
\hline Chair stand test & 0.29 & $1.35(1.07-1.69)$ & 0.010 \\
\hline \multicolumn{4}{|c|}{$\begin{array}{l}\text { Hosmer-Lemershow goodness of fit, } p=0.811 ; \text { Omnibus, } p=0.004 ; R^{2} \\
\text { Nagelkerke }=0.225 \text {. }\end{array}$} \\
\hline & \multicolumn{3}{|c|}{ Aids for walking $(n=49)$} \\
\hline & B & $\operatorname{EXP}(B)(95 \% \mathrm{Cl})$ & $p$-value \\
\hline Arm curl test & 0.19 & $1.21(1.01-1.44)$ & 0.035 \\
\hline Chair sit-and-reach test & 0.07 & $1.08(1.00-1.16)$ & 0.040 \\
\hline \multicolumn{4}{|c|}{$\begin{array}{l}\text { Hosmer-Lemershow goodness of fit, } p=0.405 ; \text { Omnibus, } \\
p=0.008 ; R^{2} \text { Nagelkerke }=0.285\end{array}$} \\
\hline
\end{tabular}

Table 5 Logistic regression models according to the QoL-AD performance adjusted by age and sex

\begin{tabular}{llll}
\hline & \multicolumn{3}{l}{ Whole sample } \\
& $\mathrm{B}$ & $\operatorname{EXP}(\mathrm{B})(95 \% \mathrm{Cl})$ & $p$-value \\
Arm curl test & 0.17 & $1.18(1.06-1.31)$ & 0.003
\end{tabular}

Variables in the model: steps/day, light physical activity, handgrip, chair stand test, arm curl test; Estimates are based on $n=99$ participants due to missing values; Hosmer-Lemershow goodness of fit, $p=0.905 ;$ Omnibus, $p=0.001 ; R^{2}$ Nagelkerke $=0.132$. No aids for walking $(n=45)$

$\begin{array}{llll} & \text { B } & \operatorname{EXP(B)}(95 \% \mathrm{Cl}) & p \text {-value } \\ \text { Light physical activity* } & 0.01 & 1.132(1.00-1.02) & 0.048\end{array}$

* One unit $=10$ min of light physical activity/day Hosmer-Lemershow goodness of fit, $p=0.911$; Omnibus, $p=0.020 ; R^{2}$ Nagelkerke $=0.152$. Aids for walking $(n=54)$

$\begin{array}{llll} & \text { B } & \operatorname{EXP}(B)(95 \% \mathrm{Cl}) & p \text {-value } \\ \text { Arm curl test } & 0.18 & 1.19(1.02-1.40) & 0.026\end{array}$

Hosmer-Lemershow goodness of fit, $p=0.545$; Omnibus, $p=0.016 ; R^{2}$ Nagelkerke $=0.136$. 
Table 6 Logistic regression models according to the Goldberg Depression Scale adjusted by age, sex and education level

\begin{tabular}{|c|c|c|c|}
\hline & \multicolumn{3}{|c|}{ Whole sample } \\
\hline & B & $\operatorname{EXP}(B)(95 \% \mathrm{Cl})$ & $p$-value \\
\hline Steps/day* & 0.001 & $1.142(1.000-1.003)$ & 0.028 \\
\hline \multicolumn{4}{|c|}{$\begin{array}{l}\text { * One unit }=100 \text { steps/day } \\
\text { Variables in the model: steps/day, light physical activity, arm curl } \\
\text { test; Estimates are based on } n=99 \text { participants due to missing } \\
\text { values; Hosmer-Lemershow goodness of fit, } p=0.031 \text {; Omnibus, } \\
p=0.000 ; R^{2} \text { Nagelkerke }=0.209 \text {. }\end{array}$} \\
\hline & \multicolumn{3}{|c|}{ No aids for walking $(n=45)$} \\
\hline & B & $\operatorname{EXP}(B)(95 \% C l)$ & $p$-value \\
\hline Steps/day* & 0.002 & $1.274(1.000-1.004)$ & 0.022 \\
\hline \multicolumn{4}{|c|}{$\begin{array}{l}\text { * One unit }=100 \text { steps } / \text { day } \\
\text { Hosmer-Lemershow goodness of fit, } p=0.326 \text {; Omnibus, } \\
p=0.001 ; R^{2} \text { Nagelkerke }=0.419\end{array}$} \\
\hline & \multicolumn{3}{|c|}{ Aids for walking $(n=54)$} \\
\hline & B & $\operatorname{EXP}(B)(95 \% C l)$ & $p$-value \\
\hline Sex (Female) & -2.169 & $0.114(0.014-0.961)$ & 0.046 \\
\hline \multicolumn{4}{|c|}{$\begin{array}{l}\text { Hosmer-Lemershow goodness of fit, } p=\text {; Omnibus, } p=0.012 ; R^{2} \\
\text { Nagelkerke }=0.159 \text {. }\end{array}$} \\
\hline
\end{tabular}

physical, cognitive and emotional functions among LT nursing home residents. Previous works have focused exclusively on high functioning older communitydwelling adults or have been largely restricted to people with cognitive impairments [37, 38]. Thus, this is the first study identifying muscle strength and physical activity as factors that could explain a better verbal memory, better QoL and lower risk of depression in older adults living in LT nursing homes.

The regression model showed that for a one-unit increase in the arm curl test (one repetition), the

Table 7 Logistic regression models according to the MEC-35 performance adjusted by age, sex and education level

\begin{tabular}{lccc}
\hline & Whole sample & \\
Chair sit-and-reach test & 0.06 & $1.06(1.02-1.11)$ & 0.006 \\
Estimates are based on $n=104$ participants due to missing values; \\
Hosmer-Lemershow goodness of fit, $p=0.587$; Omnibus, $p=0.004 ;$ \\
$R^{2}$ Nagelkerke = 0.13. \\
No aids for walking ( $n=49)$
\end{tabular}

probability of performing at or above the median on the RAVLT-AT test increased by $16 \%$. This is a novel finding of the potential mediating effects of muscle strength on the verbal memory capacity of the participants. This result is in agreement with other studies that have identified strength as a factor mediating cognitive adaptations in older adults [38-40]. Yet, data on the effects of resistance-based exercise programs on cognitive parameters are scarce. Including a combination of multiple exercise modalities, particularly resistance training, in long-term exercise programs is reported to enhance cognition in the older population to a greater extent than programs including only aerobic training [3]. In addition, the evidence concerning the possible association of muscle strength with QoL is more limited. Further, a one-unit increase in the arm curl test (one repetition) also led to a higher probability of performing at or above the median on the QoL-AD test by $18 \%$. Thus, the current study provides new data on the potential associations between muscle strength and RAVLT-AT and QoL-AD tests that warrant further investigation. It could be hypothesized that encouraging older adult living in LT nursing homes to engage in exercise programs that include resistance training could benefit not only physical but also cognitive function.

In addition, for an increase of 100 steps/day in the physical activity of the participants, the probability of being in the group with no risk of depression according to the Goldberg Depression Scale increased by $14 \%$. Hence, physical activity could be proposed as a protective factor for reducing the risk of suffering from depression. This result aligns with other studies finding that depression in older people living in nursing homes is correlated, among other factors, with the activities performed outside the nursing home [41]. Thus, the higher their level of physical activity, the more opportunities could arise for residents to visit personally meaningful places and to interact socially with others. In fact, the objectively measured physical activity of the participants was extremely low, which is consistent with previous studies reporting that nursing homes residents' life-space (that is, the spatial extension of an individual's environment that $\mathrm{s} /$ he moves in during a specified time period [42]) is severely limited to private rooms and adjacent living units [43]. Thus, nowadays, there is sufficient evidence to support the urgent implementation of interventions aimed at encouraging physical activity of older adults living in nursing homes.

For a one-unit increase in the chair sit-and-reach test (one $\mathrm{cm}$ ), the probability of performing at or above the median on the MEC-35 test increased by 
$6 \%$. This unexpected finding in the association between flexibility and MEC-35 could be masking the difficulty patients have to understand the chair sitand-reach test that we have observed during the assessments. Thus, it should be interpreted cautiously.

Our results also showed that the associations between the muscle strength and RAVLT-AT and QoL$\mathrm{AD}$ tests are different according to the use of an assistive device for walking. In those participants needing assistance, the regression models demonstrated that a one-unit increase in the arm curl test (one repetition) increased the probability of performing at or above the median on the RAVLT-AT test by $21 \%$, and on the QoL-AD test by $19 \%$. Thereby, the association between upper limb strength and RAVLT-AT test performance is higher than that found when the whole sample was analyzed (from 16\% to $21 \%$ ). In contrast, in those participants who did not need any assistive device for walking, lower limb muscle strength was the variable associated with RAVLT-AT test, and time performing light physical activity was the variable associated with QoL-AD test. Specifically, for a one-unit increase in the chair stand test (one repetition), the probability of performing at or above than the median on the RAVLT-AT test increased by $35 \%$. Further, for a $10-\mathrm{min} /$ day increase in light physical activity, the probability of being in the group with a QoL-AD test score equal to or higher than the median increased by $13 \%$. We can only speculate regarding these findings, but it could be related to how the participants used their upper or lower limbs to carry out the activities of daily life. For example, those older adults who need to incorporate the upper limbs for walking, for maintaining balance or for getting up from a chair may have undergone adaptations in the muscle physiology that could somehow influence the associations. Thereby, we surmise that participants with higher levels of well-being also have a more active lifestyle, and this could explain why they might have higher strength (this assumption could also work in the inverse sense). However, an alternative explanation could be that those individuals with a more active lifestyle could have higher strength and, consequently, might have higher levels of well-being (and vice versa).

According to the Goldberg Depression Scale and as seen for the whole cohort, the regression model in those participants that did not need aids for walking showed that for a 100-step/day increase in physical activity, the probability of being in the group with no risk of depression increased by $27 \%$. In those participants who needed aids for walking, the regression model result showed that being female increased the probability of being in the group with $50 \%$ risk of depression, according to the Goldberg Depression Scale, by $11 \%$. This result agrees with other studies where gender, specifically being female, has been identified as a risk factor for experiencing depression [44]. Nevertheless, an important limitation in this study when studying depression is the failure to consider other variables such as social support, comorbidity or pharmacology. The current study aimed at focusing only on the associations between physical conditions and depression risk, thus, these results should be interpreted cautiously.

Several molecular and physiological mechanisms have been proposed to link strength and cognition, including insulin-like growth factor, brain-derived neurotrophic factor, myokines, fibroblast growth factor 2 , and vascular endothelial growth factor $[7,45,46]$. These factors are thought to enhance neurogenesis and to play a key role in the positive effects of exercise on cognition, although the mechanisms need to be fully investigated.

There are a few limitations to this study; first, it is limited by its cross-sectional nature, precluding any ability to ascertain temporality. Second, some variables that could also be relevant, such as social support, comorbidity or pharmacology, have not been assessed and thus the results should be interpreted with caution. Third, the results cannot be directly applied to all the nursing home residents; we could not ascertain whether these results would apply to those who refused participation or did not fulfill the physical and cognitive criteria. Finally, the strength of this study is that physical activity has been objectively measured through accelerometers and that the sample size is one of the largest among studies focused on the associations between physical, cognitive and emotional aspects of the aging processes that characterize nursing home residents.

\section{Conclusions}

The present work described the associations between physical, cognitive and emotional performance in a sample of older adults living in LT nursing homes. Specifically, muscle strength and physical activity were factors associated with a better performance on the RAVLT-AT, QoL-AD and Goldberg Depression Scale. These associations appeared to differ according to the use of an assistive device for walking. Further investigation is required to understand the physiological mechanisms underlying links between skeletal muscle physiology, cognition and well-being in this vulnerable population. The results offer further evidence to support the urgent need to implement interventions directed to increase the strength and physical activity of individuals living in nursing homes, as they might benefit not only physically, but also in terms of cognitive and emotional functioning. 


\section{Appendix 1}

Table 8 Univariate logistic regression analysis with MEC-35 as dependent variable

\begin{tabular}{|c|c|c|c|}
\hline & B & $\operatorname{EXP}(B)(95 \% C l)$ & $p$-value \\
\hline Age & -0.017 & $0.983(0.931-1.038)$ & 0.539 \\
\hline Gender (Female) & 0.018 & $1.019(0.451-2.300)$ & 0.965 \\
\hline Barthel Index & 0.012 & $1.012(0.984-1.042)$ & 0.402 \\
\hline BMI & -0.033 & $0.968(0.898-1.042)$ & 0.382 \\
\hline Education (> 12 years) & 1.156 & $3.176(0.630-16.022)$ & 0.162 \\
\hline Steps/day & 0.000 & $1.000(1.000-1.000)$ & 0.336 \\
\hline Light physical activity & 0.002 & $1.002(0.995-1.008)$ & 0.579 \\
\hline MVPA & 0.362 & $1.436(0.899-2.291)$ & 0.130 \\
\hline Handgrip & 0.032 & $1.033(0.984-1.085)$ & 0.196 \\
\hline Chair stand test & -0.004 & $0.996(0.914-1.086)$ & 0.933 \\
\hline Arm curl test & 0.077 & $1.080(0.984-1.184)$ & 0.106 \\
\hline 6-min walk test & 0.002 & $1.002(0.998-1.006)$ & 0.362 \\
\hline Chair sit-and-reach test & 0.053 & $1.055(1.011-1.100)$ & $0.014^{*}$ \\
\hline Backscratch test & 0.030 & $1.031(0.999-1.064)$ & 0.059 \\
\hline 8-ft up-and-go test & -0.009 & $0.991(0.953-1.030)$ & 0.644 \\
\hline \multicolumn{4}{|c|}{$\begin{array}{l}\text { Notes: with the exception of gender and education, all the independent } \\
\text { variables are continuous } \\
\text { Abbreviations: BMI Body Mass Index, MVPA moderate-vigorous physical activity } \\
{ }^{*} p<0.05\end{array}$} \\
\hline
\end{tabular}

\section{Appendix 2}

Table 9 Univariate logistic regression analysis with Trail Making-A test as dependent variable

\begin{tabular}{|c|c|c|c|}
\hline & B & $\operatorname{EXP}(B)(95 \% C I)$ & $p$-value \\
\hline Age & 0.000 & $1.000(0.919-1.088$ & 0.997 \\
\hline Gender (Female) & 1.142 & $1.152(0.405-3.275)$ & 0.790 \\
\hline Barthel Index & -0.007 & $0.993(0.957-1.031)$ & 0.728 \\
\hline BMI & 0.000 & $1.000(0.909-1.101)$ & 0.997 \\
\hline Education (> 12 years) & 21.379 & $1,926,143,082$ & 0.999 \\
\hline Steps/day & 0.000 & $1.000(1.000-1.000)$ & 0.906 \\
\hline Light physical activity & -0.001 & $0.999(0.991-1.006)$ & 0.727 \\
\hline MVPA & -0.389 & $0.678(0.297-1.547)$ & 0.356 \\
\hline Handgrip & -0.011 & $0.989(0.932-1.049)$ & 0.718 \\
\hline Chair stand test & -0.062 & $0.940(0.837-1.054)$ & 0.289 \\
\hline Arm curl test & 0.020 & $1.020(0.906-1.149)$ & 0.740 \\
\hline 6-min walk test & -0.004 & $0.996(0.991-1.002)$ & 0.206 \\
\hline Chair sit-and-reach test & 0.022 & $1.022(0.971-1.076)$ & 0.395 \\
\hline Backscratch test & 0.038 & $1.039(0.997-1.083)$ & 0.072 \\
\hline 8-ft up-and-go test & 0.045 & $1.046(0.973-1.125)$ & 0.226 \\
\hline
\end{tabular}

Notes: with the exception of gender and education, all the independent variables are continuous

Abbreviations: BMI Body Mass Index, MVPA moderate-vigorous physical activity

\section{Appendix 3}

Table 10 Univariate logistic regression analysis with RAVLT-AT test as dependent variable

\begin{tabular}{|c|c|c|c|}
\hline & B & $\operatorname{EXP}(B)(95 \%$ Cl) & $p$-value \\
\hline Age & -0.023 & $0.978(0.921-1.038)$ & 0.460 \\
\hline Gender (Female) & 0.505 & $1.656(0.696-3.939)$ & 0.254 \\
\hline Barthel Index & -0.021 & $0.980(0.949-1.011)$ & 0.207 \\
\hline BMI & 0.032 & $1.032(0.955-1.116)$ & 0.425 \\
\hline Education (> 12 years) & -0.360 & $0.698(0.176-2.774)$ & 0.609 \\
\hline Steps/day & 0.000 & $1.000(1.000-1.001)$ & 0.237 \\
\hline Light physical activity & 0.002 & $1.002(0.995-1.009)$ & 0.532 \\
\hline MVPA & 0.098 & $1.103(0.917-1.326)$ & 0.296 \\
\hline Handgrip & 0.004 & $1.004(0.950-1.060)$ & 0.892 \\
\hline Chair stand test & 0.133 & $1.142(1.030-1.266)$ & $0.012^{*}$ \\
\hline Arm curl test & 0.148 & $1.159(1.041-1.291)$ & $0.007^{* *}$ \\
\hline 6-min walk test & 0.000 & $1.000(0.995-1.004)$ & 0.847 \\
\hline Chair sit-and-reach test & 0.053 & 1.054 (1.009-1.101) & $0.018^{*}$ \\
\hline Backscratch test & 0.013 & $1.013(0.982-1.045)$ & 0.421 \\
\hline 8-ft up-and-go test & -0.009 & $0.991(0.942-1.044)$ & 0.743 \\
\hline
\end{tabular}

\section{Appendix 4}

Table 11 Univariate logistic regression analysis with QoL-AD test as dependent variable

\begin{tabular}{llll}
\hline & $\mathrm{B}$ & $\operatorname{EXP}(\mathrm{B})(95 \% \mathrm{Cl})$ & $p$-value \\
\hline Age & -0.030 & $0.970(0.916-1.028)$ & 0.309 \\
Gender (Female) & -0.431 & $0.650(0.275-1.534)$ & 0.325 \\
Barthel Index & 0.000 & $1.000(0.970-1.032)$ & 0.975 \\
BMI & 0.036 & $1.036(0.960-1.119)$ & 0.359 \\
Education (> 12 years) & 0.563 & $1.755(0.414-7.446)$ & 0.446 \\
Steps/day & 0.001 & $1.001(1.000-1.001)$ & $0.039^{*}$ \\
Light physical activity & 0.010 & $1.010(1.002-1.019)$ & $0.019^{*}$ \\
MVPA & 0.078 & $1.082(0.916-1.276)$ & 0.354 \\
Handgrip & 0.061 & $1.063(1.005-1.125)$ & $0.034^{*}$ \\
Chair stand test & 0.110 & $1.116(1.012-1.231)$ & $0.028^{*}$ \\
Arm curl test & 0.166 & $1.181(1.059-1.317)$ & $0.003^{* *}$ \\
6-min walk test & 0.003 & $1.003(0.998-1.007)$ & 0.231 \\
Chair sit-and-reach test & 0.012 & $1.012(0.972-1.054)$ & 0.558 \\
Backscratch test & 0.002 & $1.002(0.972-1.033)$ & 0.889 \\
8-ft up-and-go test & -0.050 & $0.951(0.902-1.003)$ & 0.067 \\
\hline
\end{tabular}

Notes: with the exception of gender and education, all the independent variables are continuous

Abbreviations: BMI Body Mass Index, MVPA moderate-vigorous physical activity ${ }^{*} p<0.05$ $p<0.01$ 


\section{Appendix 5}

Table 12 Univariate logistic regression analysis with Goldberg Depression Scale as dependent variable

\begin{tabular}{llll}
\hline & $\mathrm{B}$ & EXP(B) (95\% Cl) & $p$-value \\
\hline Age & -0.043 & $0.958(0.895-1.025)$ & 0.216 \\
Gender (Female) & -1.498 & $0.224(0.062-0.812)$ & $0.023^{*}$ \\
Barthel Index & 0.002 & $1.002(0.968-1.038)$ & 0.895 \\
BMI & -0.024 & $0.976(0.896-1.063)$ & 0.579 \\
Education (> 12 years) & 1.094 & $2.985(0.355-25.094)$ & 0.314 \\
Steps/day & 0.002 & $1.002(1.000-1.003)$ & $0.008^{* *}$ \\
Light physical activity & 0.014 & $1.014(1.003-1.026)$ & $0.014^{*}$ \\
MVPA & 0.098 & $1.103(0.852-1.428)$ & 0.456 \\
Handgrip & 0.067 & $1.070(0.997-1.148)$ & 0.061 \\
Chair stand test & 0.108 & $1.114(0.999-1.243)$ & 0.051 \\
Arm curl test & 0.177 & $1.194(1.052-1.356)$ & $0.006^{* *}$ \\
6-min walk test & 0.002 & $1.002(0.997-1.007)$ & 0.431 \\
Chair sit-and-reach test & 0.033 & $1.033(0.984-1.084)$ & 0.188 \\
Backscratch test & -0.006 & $0.994(0.959-1.030)$ & 0.749 \\
8-ft up-and-go test & -0.025 & $0.975(0.923-1.029)$ & 0.360
\end{tabular}

Notes: with the exception of gender and education, all the independent variables are continuous

Abbreviations: BMI Body Mass Index, MVPA moderate-vigorous physical activity ${ }^{*} p<0.05$

$p<0.001$

\section{Appendix 6}

Table 13 Variables that reached statistical significance on univariate logistic regression models according to the MEC-35, RAVLT-AT, QoL-AD and Goldberg depression scale

\begin{tabular}{|c|c|c|c|c|}
\hline & & B & $\operatorname{EXP}(B)(95 \% C l)$ & $p$-value \\
\hline MEC-35 & $\begin{array}{l}\text { Chair sit and } \\
\text { reach test }\end{array}$ & 0.053 & $1.055(1.011-1.100)$ & 0.014 \\
\hline \multirow[t]{3}{*}{ RAVLT-AT } & Chair stand test & 0.133 & $1.142(1.030-1.266)$ & 0.012 \\
\hline & Arm curl test & 0.148 & $1.159(1.041-1.291)$ & 0.007 \\
\hline & $\begin{array}{l}\text { Chair sit-and- } \\
\text { reach test }\end{array}$ & 0.053 & $1.054(1.009-1.101)$ & 0.018 \\
\hline \multirow[t]{5}{*}{ QoL-AD } & Steps/day & 0.001 & $1.001(1.000-1.001)$ & 0.039 \\
\hline & $\begin{array}{l}\text { Light physical } \\
\text { activity }\end{array}$ & 0.010 & $1.010(1.002-1.019)$ & 0.019 \\
\hline & Handgrip & 0.061 & $1.063(1.005-1.125)$ & 0.034 \\
\hline & Chair stand test & 0.110 & $1.116(1.012-1.231)$ & 0.028 \\
\hline & Arm curl test & 0.166 & $1.181(1.059-1.317)$ & 0.003 \\
\hline \multirow[t]{4}{*}{$\begin{array}{l}\text { Goldberg } \\
\text { Depression Scale }\end{array}$} & $\begin{array}{l}\text { Gender } \\
\text { (Female) }\end{array}$ & -1.498 & $0.224(0.062-0.812)$ & 0.023 \\
\hline & Steps/day & 0.002 & $1.002(1.000-1.003)$ & 0.008 \\
\hline & $\begin{array}{l}\text { Light physical } \\
\text { activity }\end{array}$ & 0.014 & $1.014(1.003-1.026)$ & 0.014 \\
\hline & Arm curl test & 0.177 & $1.194(1.052-1.356)$ & 0.006 \\
\hline
\end{tabular}

Notes: with the exception of gender, all the independent variables are continuous

\section{Abbreviations}

6MWT: 6 Minutes walking test; LT: Long term; MEC-35: Mini Examen Cognoscitivo-35; MVPA: Moderate to vigorous physical activity; QoL: Quality of life; QoL-AD: Quality of life-Alzheimer's disease; RAVLT: Rey Auditory-Verbal Learning Test; SFT: Senior Fitness Test

\section{Acknowledgements}

We would like to thank all study participants and their families for their cooperation and their confidence in the research team. The authors also would like to express their gratitude to all the nursing home staff for their time and cooperation during the fieldwork process.

\section{Funding}

This study was supported by a Project from the Basque Government (ELKARTEK 15/39; №. EXPT: KK-2015/00106). Specifically, the role of the funding body in this piece of research was directed to the acquisition of the material for the assessments (e.g. accelerometers, dumbbells, chronometers, chairs) and to the displacement of the researchers to the nursing homes. Haritz Arrieta, Chloe Rezola and Iñaki Echeverria were supported by fellowships from University of the Basque Country (UPV/EHU) to undertake their doctoral research.

\section{Availability of data and materials}

The database set was available to all authors of the study and are available from the corresponding author on non-commercial and reasonable request.

\section{Authors' contributions}

HA, SG, JY, JI, MI and AR participated in the design of the study. MI, HA and AR participated in the recruitment process of the participants. HA, CR and IE were responsible for data collection. AR and $J$ performed the statistical analyses. HA, CR, IE, MI, SG, JY, JI, and AR drafted the manuscript. All authors read and approved the final version of the manuscript.

\section{Ethics approval and consent to participate}

The present study has been approved by the Committee on Ethics in Research of the University of the Basque Country (Humans Committee Code M10/2016/105) and has also received a letter of support from the senior administrator of Matia, Caser Residential Care Facilities, lurreamendi and Uzturre Nursing Homes. Furthermore, the study protocol has been registered under the Australian and New Zealand Clinical Trials Registry (ANZCTR) with the identifier: ACTRN12616001044415 and all participants have provided written informed consent based on documents approved by the University of the Basque Country Institutional Review Board. The study has been carried out in accordance with Good Clinical Practice, applicable local regulatory requirements, and the guiding principles of the Declaration of Helsinki. Universal Trial Number U1111-1185-6368.

\section{Consent for publication}

Not applicable.

\section{Competing interests}

The authors declare that they have no competing interest.

\section{Publisher's Note}

Springer Nature remains neutral with regard to jurisdictional claims in published maps and institutional affiliations.

\section{Author details}

${ }^{1}$ Department of Physiology, Faculty of Medicine and Nursing, University of the Basque Country (UPV/EHU), Barrio Sarriena s/n, E-48940 Leioa, Bizkaia, Spain. ${ }^{2}$ Matia Instituto Gerontológico Foundation, Camino de los Pinos 35, E-20018 Donostia-San Sebastian, Gipuzkoa, Spain.

Received: 4 October 2017 Accepted: 15 March 2018

Published online: 27 March 2018

\section{References}

1. Robertson DA, Savva GM, Kenny RA. Frailty and cognitive impairment-a review of the evidence and causal mechanisms. Ageing Res Rev. 2013;12(4): 840-51. https://doi.org/10.1016/j.arr.2013.06.004. 
2. Brisswalter J, Collardeau M, Arcelin R. Effects of acute physical exercise characteristics on cognitive performance. Sports Med. 2002;32:555-66. https://doi.org/10.2165/00007256-200232090-00002.

3. Colcombe $S$, Kramer AF. Fitness effects on the cognitive function of older adults: a meta-analytic study. Psychol Sci. 2003;14:125-30. https://doi.org/10. 1111/1467-9280.t01-1-01430.

4. Voss MW, Vivar C, Kramer AF, Van Praag H. Bridging animal and human models of exercise-induced brain plasticity. Trends Cogn Sci. 2013;17:52544. https://doi.org/10.1016/j.tics.2013.08.001.

5. Billinger SA, Vidoni ED, Morris JK, Thyfault JP, Burns JM. Exercise test performance reveals evidence of the cardiorespiratory fitness hypothesis. J Aging Phys Act. 2017;25(2):240-6. https://doi.org/10.1123/japa.2015-0321.

6. Hsu CL, Best JR, Wang S, Voss MW, Hsiung RGY, Munkacsy M, et al. The impact of aerobic exercise on Fronto-parietal network connectivity and its relation to mobility: an exploratory analysis of a 6-month randomized controlled trial. Front Hum Neurosci. 2017;11 https://doi.org/10.3389/fnhum. 2017.00344.

7. Chang YK, Pan CY, Chen FT, Tsai CL, Huang CC. Effect of resistance-exercise training on cognitive function in healthy older adults: a review. J Aging Phys Act. 2012;20(4):497-517.

8. Phillips CB, Edwards JD, Andel R, Kilpatrick M. Daily physical activity and cognitive function variability in older adults. J Aging Phys Act. 2016;24(2): 256-67. https://doi.org/10.1123/japa.2014-0222.

9. Kraft E. Cognitive function, physical activity, and aging: possible biological links and implications for multimodal interventions. Neuropsychol Dev Cogn B Aging Neuropsychol Cogn. 2012;19:248-63. https://doi.org/10.1080/ 13825585.2011.645010.

10. Penedo FJ, Dahn JR. Exercise and well-being: a review of mental and physical health benefits associated with physical activity. Curr Opin Psychiatry. 2005;18: 189-93. https://doi.org/10.1097/00001504-200503000-00013.

11. Birch K, Ten Hope M, Malek-Ahmadi M, O'Connor K, Schofield S, Coon D, et al. Cognitive function as a mediator in the relationship between physical activity and depression status in older adults. J Aging Phys Act. 2016;24(4): 540-6. https://doi.org/10.1123/japa.2015-0029.

12. Balboa-Castillo T, León-Muñoz LM, Graciani A, León-Muñoz LM, Graciani A, Rodríguez-Artalejo F, et al. Longitudinal association of physical activity and sedentary behavior during leisure time with health-related quality of life in community-dwelling older adults. Health Qual Life Outcomes. 2011;9(1):47. https://doi.org/10.1186/1477-7525-9-47.

13. Prince $M$, Prina $M$, Guerchet $M$. Journey of caring, an analysis of long-term Care for Dementia. World Alzheimer report 2013 executive summary. Alzheimer's disease international (ADI). London. http://www.alz.co.uk/ research/WorldAlzheimerReport2013.pdf. Accessed 20 Mar 2018.

14. Bercovitz A, Dwyer LL, Jones A, Strahan GW. The National Nursing Home Survey: 2004 overview. Vital Health Stat. 2009;13:1-155.

15. Miskelly F. Electronic tracking of patients with dementia and wandering using mobile phone technology. Age Ageing. 2005;34:497-9. https://doi. org/10.1093/ageing/afi145.

16. Castle NG, Ferguson JC. What is nursing home quality and how is it measured? Gerontologist. 2010;50(4):426-42. https://doi.org/10.1093/geront/gnq052.

17. Wiener JM. An assessment of strategies for improving quality of care in nursing homes. Gerontologist. 2003;43(suppl 2):19-27. https://doi.org/10. 1093/geront/43.suppl_2.19.

18. Den Ouden M, Bleijlevens MH, Meijers JM, Zwakhalen SM, Braun SM, Tan FE, et al. Daily (in) activities of nursing home residents in their wards: an observation study. J Am Med Dir Assoc. 2015;16(11):963-8. https://doi.org/ 10.1016/j.jamda.2015.05.016.

19. Ice GH. Daily life in a nursing home: has it changed in 25 years? J Aging Stud. 2002;16(4):345-59. https://doi.org/10.1016/S0890-4065(02)00069-5.

20. Rodriguez-Larrad A, Arrieta H, Rezola C, Kortajarena M, Yanguas JJ, Iturburu $M$, et al. Effectiveness of a multicomponent exercise program in the attenuation of frailty in long-term nursing home residents: study protocol for a randomized clinical controlled trial. BMC Geriatr. 2017;17(1):60. https:// doi.org/10.1186/s12877-017-0453-0.

21. Wade DT, Collin C. The Barthel ADL index: a standard measure of physical disability? Int Disabil Stud. 1988;10(2):64-7. https://doi.org/10.3109/ 09638288809164105

22. Lobo A, Saz P, Marcos G, Día JL, De la Cámara C, Ventura T, et al. Revalidación y normalización del Mini-Examen Cognoscitivo (primera versión en castellano del Mini-Mental Status Examination) en la población general geriátrica. Med Clin (Barc). 1999;112(20):767-74.
23. Freedson PS, Melanson E, Sirard J. Calibration of the computer science and applications Inc. accelerometer. Med Sci Sports Exerc. 1998;30(5):777-81. https://doi.org/10.1097/00005768-199805000-00021.

24. Fess E. Clinical assessment recommendations. Grip strength. In: Casanova JS, editor. . 2nd ed. Chicago: American Society of Hand Therapists; 1992. p. 41-5.

25. Rikli RE, Jones CJ. Senior fitness test. Champaign: human kinetics; 2001. ISBN 0-7360-3356-4.

26. Reitan RM, Wolfson D. The Halstead-Reitan neuropsychological test battery: theory and clinical interpretation (Vol. 4). Reitan neuropsychology; 1985.

27. Ponton MO. Research and assessment issues with Hispanic populations. In: Neuropsychology and the Hispanic patient: a clinical handbook. Mahwah, NJ: Lawrence Erlbaum Associates; 2001. p. 39-58.

28. Ivnik RJ, Malec JF, Tangalos ER, Petersen RC, Kokmen E, Kurland LT. The auditory-verbal learning test (AVLT): norms for ages 55 years and older. Psychol Assessment. 1990;2:304-12. https://doi.org/10.1037/1040-3590.2.3.304.

29. Gómez-Gallego M, Gómez-Amor J, Gómez-García J. Validación de la versión española de la escala QoL-AD en pacientes con enfermedad de Alzheimer, cuidadores y profesionales sanitarios. Neurologia. 2012;27(1):4-10. https:// doi.org/10.1016/j.nrl.2011.03.006.

30. Goldberg D, Bridges K, Duncan-Jones P, Grayson D. Detecting anxiety and depression in general medical settings. BMJ. 2012;297(6653):897-9.

31. Ferrer A, Formiga F, Almeda J, Alonso J, Brotons C, Pujol R. Calidad de vida en nonagenarios: género, funcionalidad y riesgo nutricional como factores asociados. Med Clin (Barc). 2010;13:303-6. https://doi.org/10.1016/j.medcli.2009.06.070.

32. Pereira C, Fernandes J, Raimundo A, Biehl-Printes C, Marmeleira J, Tomas-Carus $P$. Increased physical activity and fitness above the 50th percentile avoid the threat of older adults becoming institutionalized: a cross-sectional pilot study. Rejuvenation Res. 2016;19(1):13-20. https://doi.org/10.1089/rej.2015.1669.

33. Vidoni ED, Johnson DK, Morris JK, Van Sciver A, Greer CS, Billinger SA, et al. Dose-response of aerobic exercise on cognition: a community-based, pilot randomized controlled trial. PLoS One. 2015;10(7):e0131647. https://doi.org/ 10.1371/ journal.pone.0131647.

34. Liu-Ambrose T, Nagamatsu LS, Graf P, Beattie BL, Ashe MC, Handy TC. Resistance training and executive functions: a 12-month randomized controlled trial. Arch Intern Med. 2010;170(2):170-8. https://doi.org/10.1001/ archinternmed.2009.494.

35. Angevaren M, Aufdemkampe G, Verhaar H. Physical activity and enhanced fitness to improve cognitive function in older people without known cognitive impairment. Cochrane Database Syst Rev. 2008;3(3) https://doi. org/10.1002/14651858.CD005381.pub3.

36. Angevaren M, Vanhees L, Wendel-Vos W, Verhaar HJ, Aufdemkampe G, Aleman A, et al. Intensity, but not duration, of physical activities is related to cognitive function. Eur J Cardiovasc Prev Rehabil. 2007;14(6):825-30. https:// doi.org/10.1097/HJR.0b013e3282ef995b.

37. Berryman N, Bherer L, Nadeau S, Lauzière S, Lehr L, Bobeuf F, et al. Executive functions, physical fitness and mobility in well-functioning older adults. Exp Gerontol. 2013;48(12):1402-9. https:/doi.org/10.1016/j.exger.2013.08.017.

38. Mavros Y, Gates N, Wilson GC, Jain N, Meiklejohn J, Brodaty H, et al. Mediation of cognitive function improvements by strength gains after resistance training in older adults with mild cognitive impairment: outcomes of the study of mental and resistance training. J Am Geriatr Soc. 2017;65(3):550-9. https://doi.org/10.1111/jgs.14542.

39. Boyle PA, Buchman AS, Wilson RS, Leurgans SE, Benett DA. Association of muscle strength with the risk of Alzheimer disease and the rate of cognitive decline in community-dwelling older persons. Arch Neurol. 2009:66:1339_ 44. https://doi.org/10.1001/archneurol.2009.240.

40. Tolea MI, Galvin JE. Sarcopenia and impairment in cognitive and physical performance. Clin Interv Aging. 2015;10:663-71. https://doi.org/ 10.2147/CIA.S76275.

41. Patra P, Alikari V, Fradelos EC, Sachlas A, Kourakos M, Gil APR, et al. Assessment of depression in elderly. Is perceived social support related? A nursing home study. Adv Exp Med Biol. 2017;987:139-50. https://doi.org/10. 1007/978-3-319-57379-3_13.

42. Tsai LT, Portegijs E, Rantakokko M, Viljanen A, Saajanaho M, Eronen J, et al. The association between objectively measured physical activity and lifespace mobility among older people. Scand J Med Sci Sports. 2015;25(4): e368-73. https://doi.org/10.1111/sms.12337.

43. Jansen CP, Diegelmann M, Schnabel EL, Wahl HW, Hauer K. Life-space and movement behavior in nursing home residents: results of a new sensorbased assessment and associated factors. BMC Geriatr. 2017:17(1):36. https:// doi.org/10.1186/s12877-017-0430-7. 
44. Tintle N, Bacon B, Kostyuchenko S, Gutkovich Z, Bromet EJ. Depression and its correlates in older adults in Ukraine. Int J Geriatr Psychiatry. 2011;26(12): 1292-9. https://doi.org/10.1002/gps.2681.

45. Pratesi A, Tarantini F, Di Bari M. Skeletal muscle: an endocrine organ. Clin Cases Miner Bone Metab. 2013;10(1):11. https://doi.org/10.11138/ccmbm/ 2013.10.1.011.

46. Meng SJ, Yu LJ. Oxidative stress, molecular inflammation and sarcopenia. Int J Mol Sci. 2010;11(4):1509-26. https://doi.org/10.3390/ijms11041509.

Submit your next manuscript to BioMed Central and we will help you at every step:

- We accept pre-submission inquiries

- Our selector tool helps you to find the most relevant journal

- We provide round the clock customer support

- Convenient online submission

- Thorough peer review

- Inclusion in PubMed and all major indexing services

- Maximum visibility for your research

Submit your manuscript at www.biomedcentral.com/submit 